\title{
REDUCING SILTATION IN THE JUIST MARINA IDENTIFICATION OF SEDIMENT TRANSPORT MECHANISMS BY IN SITU MEASUREMENTS AND EVALUATION OF CONSTRUCTIONAL MEASURES USING NUMERICAL MODELLING
}

\author{
Jan Saalbach ${ }^{1}$, Anna Zorndt ${ }^{2}$, Knut Krämer ${ }^{2}$, Torsten Schlurmann ${ }^{3}$
}

\section{Introduction}

The East Frisian island of Juist is situated $10 \mathrm{~km}$ off the German North Sea Coast in the Wadden Sea (see Figure 1) In recent years its municipal port has been complemented with a marina which is facing high siltation leading to dredging expenses and frequencies considerably higher than anticipated. Mainly fine sands are transported into the basin and deposited behind the marina entrance. Silt is transported farther and aggregates in the marina basin leading to rapid siltation and limiting accessibility for shipping (see Figure 2). In this poster methods for measurement, analysis and quantification of sediment transport mechanisms in the port of Juist are presented. Furthermore, numerical simulations based on the findings of the analysis of the status quo are carried out to evaluate different constructional options aiming for an optimization of the marina design.

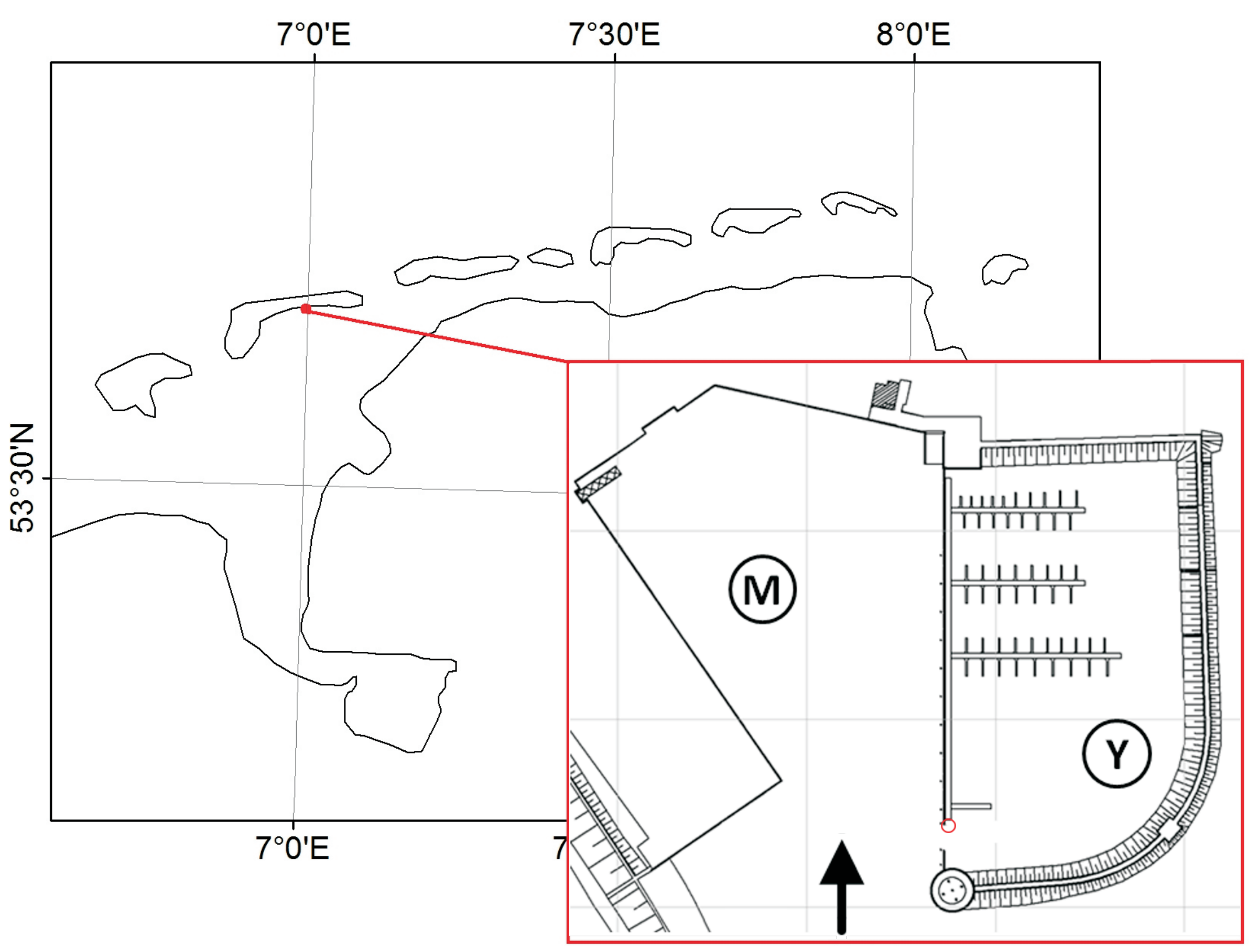

Fig. 1: Location of the island of Juist and plan view of the municipal port $(\mathrm{M})$ and marina $(\mathrm{Y})$ seperated by a bulkhead.
Arrow denotes common port entrance at the northern Arrow denotes common port entrance at the northern
end of the approach channel. Red circle marks position of the long term measurement station.

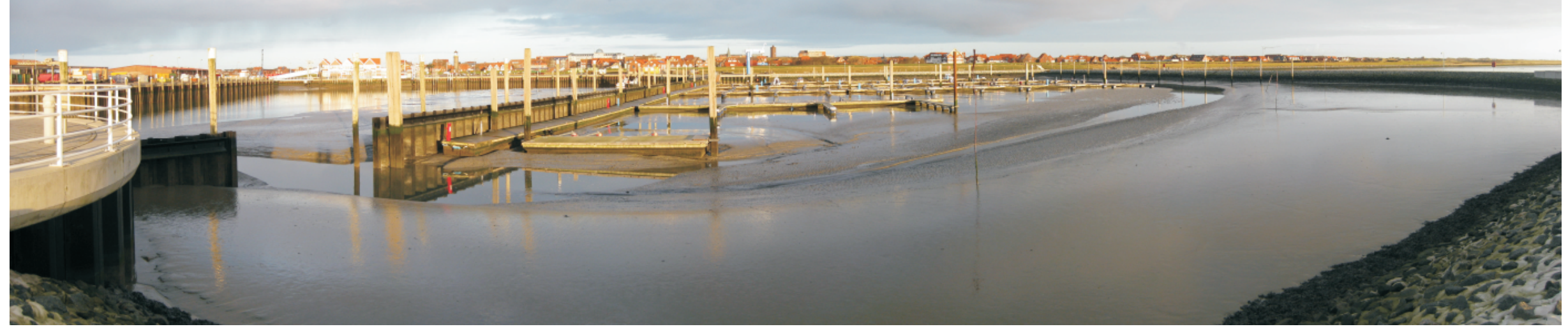

Fig. 2: Panorama view of the Juist marina at low tide.

\section{Methods}

\subsection{Measurements}

In order to determine the variation in hydro- and morphodynamic parameters throughout a spring-neap cycle, a long term monitoring station consisting of a pressure gauge, an electromagnetic current sensor (EMS) and two optical backscatter sensors (OBS) was installed in the marina entrance. Water level, current velocity and suspended sediment concentration (ssc) at two levels were recorded over a period of 30 days. The OBSs were calibrated with water and sediment samples taken at the study site. Based on these measurements, flood and ebb duration were defined according to change in flow direction. Sediment fluxes for flood and ebb periods were calculated by integrating flow velocities and ssc over the cross sectional area of the marina entrance. Based on the sediment fluxes mass balances of sediment in- and outflow over individual tida cycles were computed. To illustrate differences between spring, neap and normal tide, representative cycles for each state were constructed by averaging several measurements covering one cycle each.

In two measuring campaigns performed during spring and low tide conditions, respectively GPS drifter measurements as well as vessel based ADCP measurements were carried out to characterize the overall flow and transport pattern in the municipal port and adjacent marina during ebb and flood current. The GPS drifters follow the direction of near surface flow and thus make up for the restriction of the ADCP in the upper part of the water column. The low-cost GPS drifters have been developed in cooperation with the Institute of Geodesy of Leibniz Universität Hannover (Vennebusch et al., 2012).

\subsection{Numerical Simulations}

Following the evaluation of aforementioned measurements a numerical model of the municipal port and marina was set up to remodel hydro- and morphodynamic phenomena in the port of Juist A triangular unstructured mesh was generated based on high resolution bathymetric data obtained by airborne laser scanning and multibeam echo soundings. Hydrodynamical and morphological data obtained during the measuring campaigns were used for the calibration of the numerical model. Model runs were then carried out using the 3D finite-element circulation modeling tool SELFE (Zhang and Baptista, 2008).

After the model had been set up and calibrated, different design options aiming at an improvement of the sedimentation problems were defined in consultation with local authorities as well as port and marina operators. The constructional alternatives were investigated numerically. The option favored by marina operators was a widening of the marina entrance at its current position as it does not involve any rearangement of jetties or redesign of the overall marina. Model runs were set up to investigate the efficiency of the design alternatives in reducing siltation problems in the marina.

\section{Results}

\subsection{Measurements}

The evaluation of the long term measurements illustrates a strong tidal asymmetry exhibiting high velocities during a short flood phase and lower velocities during a longer ebb phase. Accordingly, high concentrations of suspended sediment are found during flood current, whereas ssc is reasonably lower during ebb current. Water level, flow velocity and sediment load for an average spring cycle can be found in Figure 3 . It is obvious that the low flow velocities and ssc integrated over the period of ebb current do not match the sediment volume transported into the basin during flood current. Therefore, the sediment mass balance over a full tidal cycle shows a net sediment flux into the marina basin. The integrated sediment influx was found to be twice as high during spring tides as during neap tides or medium conditions.

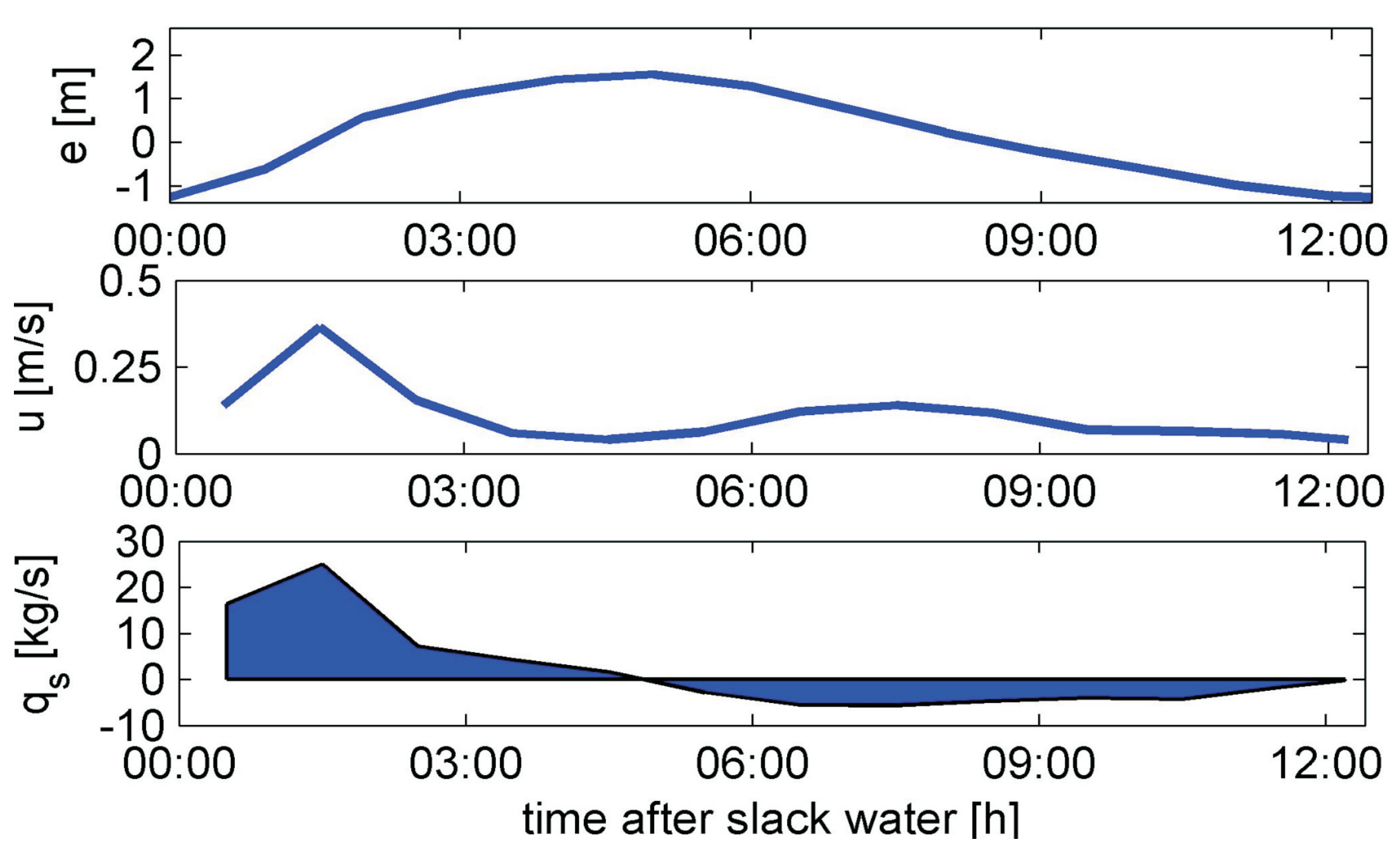

Fig. 3: Hourly mean values for water level, flow velocity and sediment flux for an average spring cycle.

The overall flow field in the port area captured by ADCP and GPS drifter measurements shows high flow velocities in the approach channel during flood current. At the entrance to the marina a decrease in flow velocities can be observed. Spatial ADCP velocity distribution and drifter pathways in the port and marina from the spring flood campaign are depicted in Figure 4.

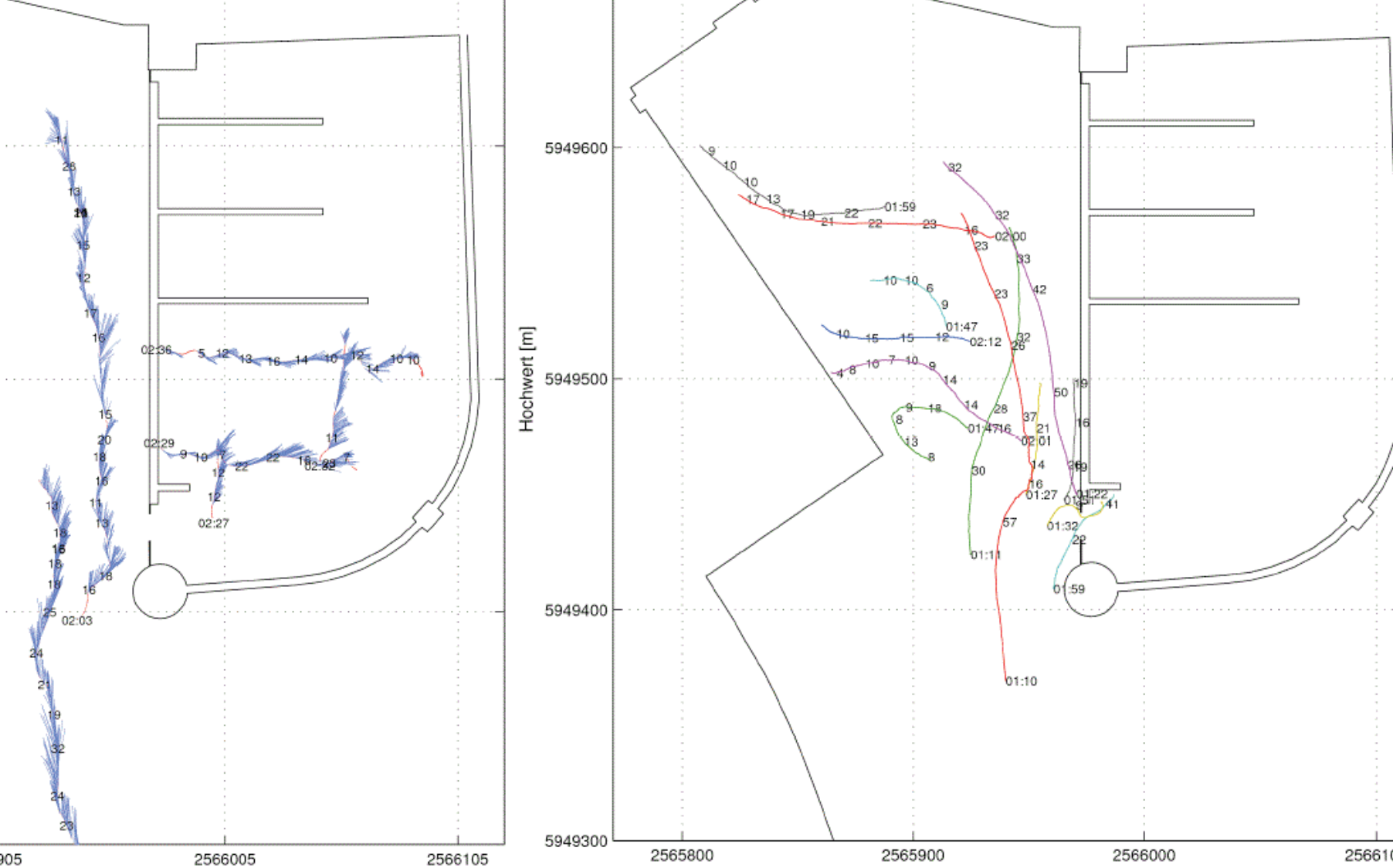

Fig. 4: Spatial velocity distribution in the port during spring flood. Left panel shows depth averaged ADCP velocities. Right panel shows GPS drifter pathways.

\subsection{Numerical Model}

The results from the numerical model runs show a good representation of the flow pattern as recorded by ADCP and drifter measurements. The differences between flood and ebb current as well as between spring and neap conditions are reflected in the model runs. Flow velocities during spring flood and ebb current can be found in Figure 5. It can be seen that flow velocities and therefore suspension and transport capacities are reasonably higher during flood current. A certain drop in flow velocities at the end of the approach channel due to the sudden widening of the effective flow area leads to the aggregation of sandy material which is suspended in the approach channel and transported into the port.
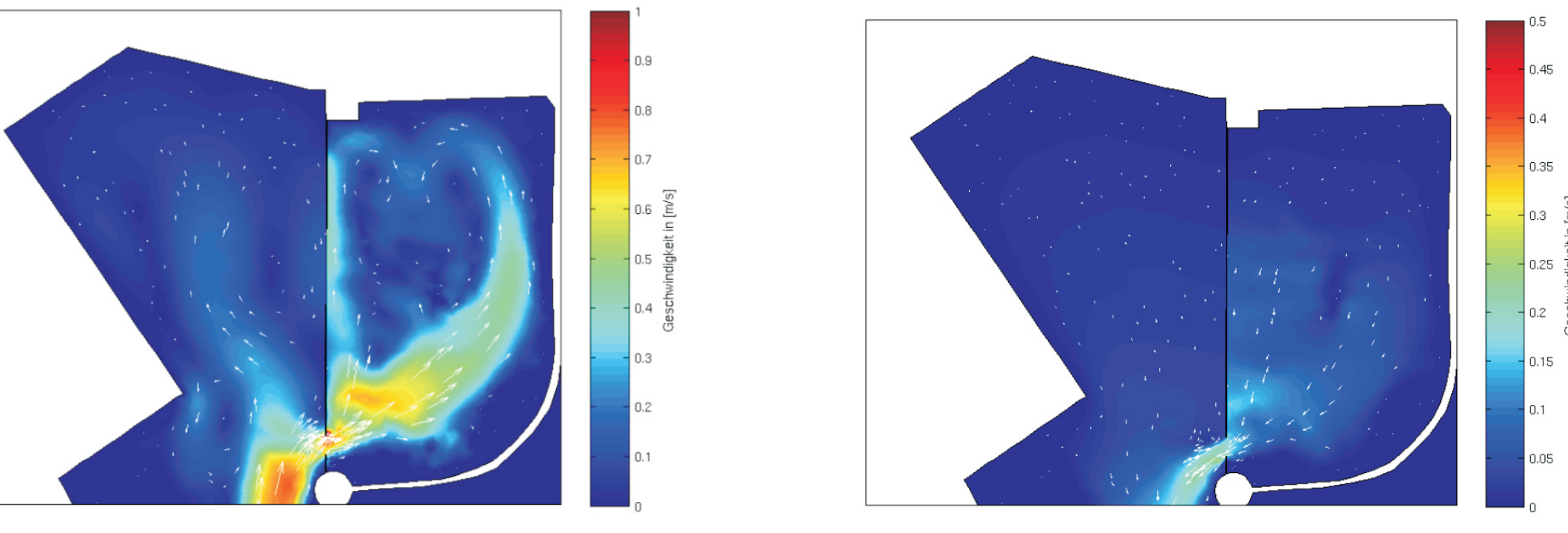

Fig. 5: Snapshots of flow pattern and velocities obtained from the mode. Lower panels show water level and time of the rent, upper right panel shows spring ebb current Velocities given in $\mathrm{m} / \mathrm{s}$. Note the different scaling of the velocity color bars.

The evaluation of the morphodynamic simulations for the favored design alternative with a widened marina entrance in comparison to the current state shows that it will supposedly not help to reduce sedimentation in the marina basin. Figure 6 shows a comparison between the current state and the design alternative from two morphodynamic model runs.
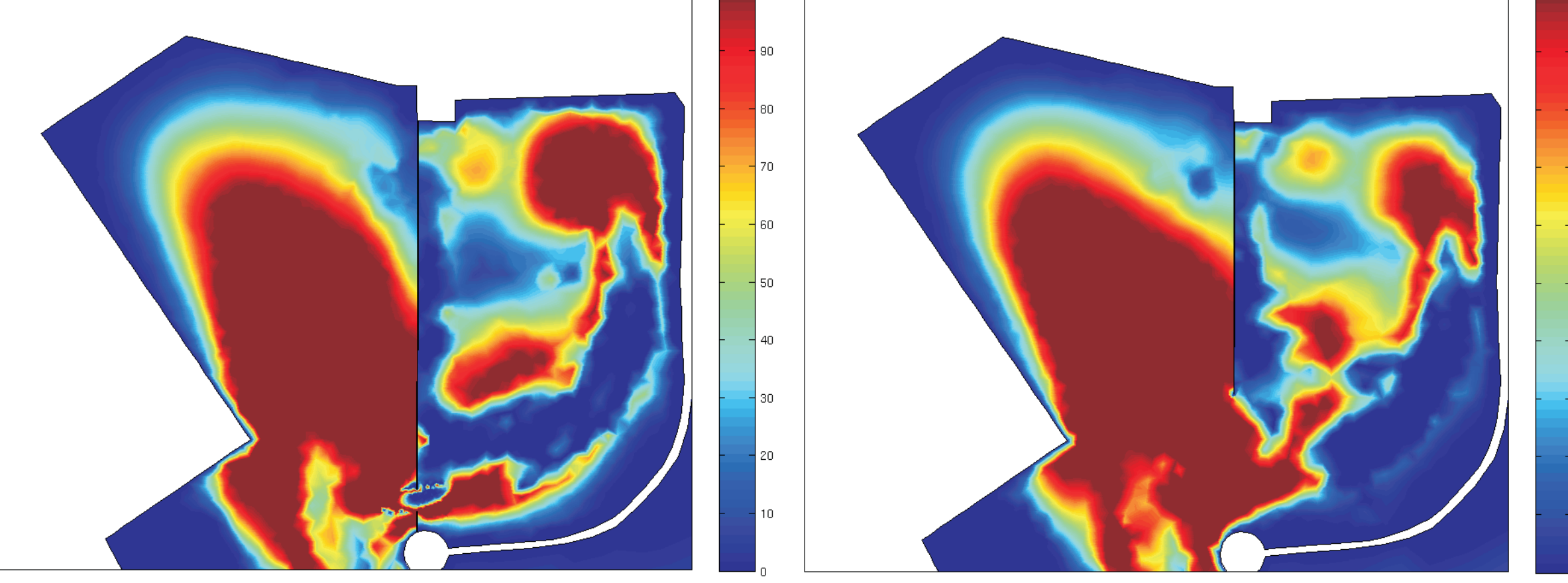

in percent of maximum value after days of model run time. Left panel shows current marina entrance design. Right panel shows the favoured design option with a widened marina entrance.

\section{Summary and Outlook}

The combination of long term stationary measurements of velocities and sediment concentration and spatial velocity measurements helped to understand the overall flow pattern and sediment transport pathways in the port area. Fine sands suspended in the approach channel are transported to the marina entrance and deposited there due to the diminished transport capacity of the current. The deposited sandy material forms a sand bar at the marina entrance, making the marina basin act as a sediment trap fo silty sediments which can not be re-suspended by the slow ebb

The data collected during the long term measurement and vessel based campaigns were used to set up and calibrate numerical model of the port area. The model was then used to evaluate the effects of a redesign or relocation of the marina entrance on sediment dynamics. It was found that a simple widening of the marina entrance will nor help to reduce siltation problems. Other design options are currently being discussed among port and marina operators as they require a rearrangement of jetties and a complete redesign of the marina.

\section{References}

nebusch M., Albert L., Schön S., Kube F., Goseberg N., ZorndtA., Schlurmann T., Wurpts A., 2012
Precise Determination of Sediment Dnnamics Using Low-cost GPS-floaters, IEEEIION PLANS n,Y.Baptista, A., 2008. SELFE: A semi-implicit Eulerian-Lagrangian finite-element model for

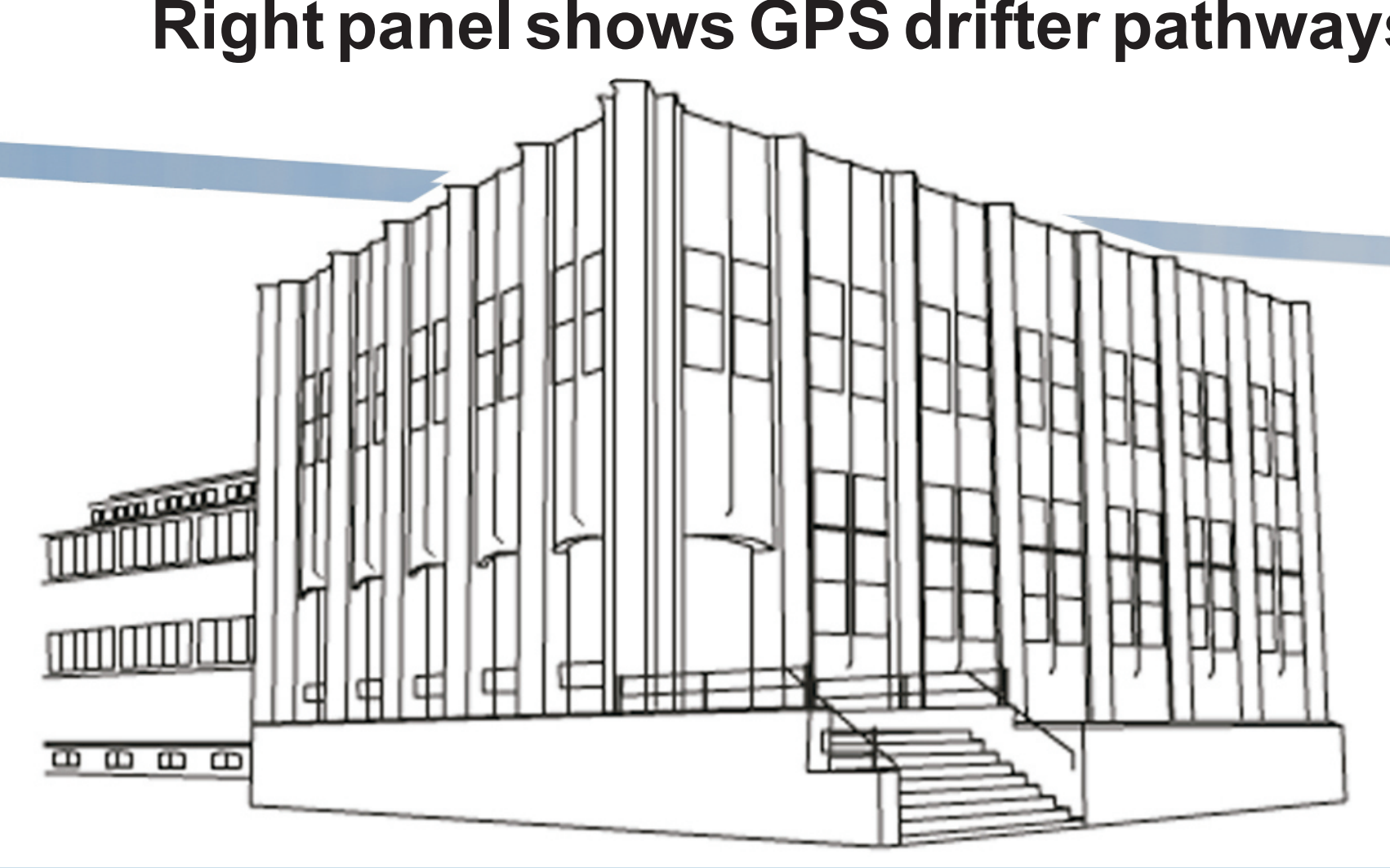

Franzius-Institute for Hydraulic,

Waterways and Coastal Engineering

Leibniz Universität Hannover

Nienburger Str. 4

D-30167 Hannover, Germany. 